\title{
SEMIÓTICA PSICANALÍTICA PARA CRIANÇAS DE 0-99 ANOS-LUZ
}

\author{
Psychoanalytical semiotics for 0-99 light-years \\ old children
}

Semiótica psicoanalítica para niños de 0-99 años luz

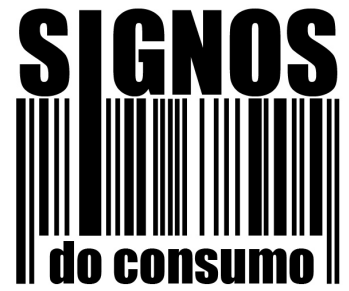

entrevista

\author{
Oscar Cesarotto \\ Universidade de São Paulo, São Paulo, Brasil. \\ Psicanalista. Doutor em Comunicação e Semiótica; professor da Pontifícia Universidade Católica \\ de São Paulo; autor de vários livros; coordenador do curso Semiótica Psicanalítica - Clínica da \\ Cultura (COGEAE-PUC). Professor e tutor no curso de pós-graduação Cultura Material e Consumo: \\ perspectivas semiopsicanalíticas, da Escola de Comunicações e Artes da Universidade de São Paulo. \\ E-mail: oscarangel@bol.com.br
}

Perguntas, questões, curiosidades... Che vuoi? Qual é a sua?

Resposta: a responsabilidade de ter uma episteme para explicar a quem quiser saber, de forma preclara e imprecisa, o que realmente está em jogo na contemporaneidade. A priori, mesmo que a psicanálise seja assaz conhecida, o mundo ignora o que a semiótica seria; se fosse, ainda por cima, psicanalítica, nossa!

A nossa semiótica considera os signos hegemônicos como determinantes da existência individual e social. No entanto somos seres simbólicos, sujeitos à lei da linguagem, porém reféns das pulsões. Nas soluções de compromisso de cada falante, sexuado e mortal, transcorre a vida cotidiana, psicopatológica. No plano coletivo, conflitos e contradições que afetam a todos constituem a linha de pesquisa da clínica da cultura, o campo do gozo, o inconsciente a céu aberto.

Com a finalidade de pontificar sobre alguns assuntos relevantes, achei por bem redigir esta entrevista fictícia, estruturada a partir de demandas verdadeiras. Ao longo dos anos, são frequentes alguns temas sempre em pauta. Rememorando e atualizando diálogos, debates e outras inquisições, dir-se-ia ${ }^{1}$ :

SC: Semiótica e psicanálise? Por quê? Onde, quando e como?

Nos anos 1980, as professoras Samira Chalhub e Lucia Santaella, do Programa de Comunicação e Semiótica da Pontifícia Universidade Católica de São Paulo (PUC-SP), começaram a estudar psicanálise especificamente, a obra de Lacan - para compensar a ausência, nas teorias semióticas tradicionais, do lugar do sujeito; isto é, do inconsciente. Por motivos de nomenclatura, a linha de pesquisa foi denominada semiótica psicanalítica, de forma conjuntiva, não por um termo qualificar o outro. As bagagens das linguagens que conformam o fenômeno humano expandem o saber psicanalítico, que contribui expondo os labirintos desiderativos da subjetividade.

1. As siglas que surgem ao longo da entrevista são um recurso estilístico do autor para dar voz a um sujeito coletivo, que tem se manifestado ao longo desses mais de 30 anos de pesquisa, docência e trabalho em semiótica e psicanálise. 


\section{ARS: Freud teria cabimento?}

Pelas raízes, conhecerás a árvore e seus frutos... A nossa bíblia laica, Obras completas, é a pedra basal da viga mestra da laje da planta onde hoje pisamos. Freud foi um semioticista avant la lettre, como prova a Interpretação dos sonhos (1900), um autêntico tratado sobre signos e símbolos, mesmo sem dispor, na época, de uma teoria consistente sobre a função e o campo da palavra. Décadas depois, Lacan introduziria a linguística como discurso competente para dar conta do inconsciente estruturado segundo a linguagem. Entretanto, Freud continua imprescindível para as ciências humanas por ser um dos seus maiores mentores. Enquanto Totem e tabu (1912) especula sobre a origem da lei e da obediência, Psicologia das massas (1920) revela o poder de líderes e ideais no vértice da pirâmide da dominação civilizatória; $O$ futuro de uma ilusão (1927) desconstrói as promessas ocas da religião; e Malestar na cultura (1930) parece antecipar os noticiários atuais, com suas interpretações sombrias sobre o funcionamento da sociedade e o peso da cultura.

LG: Como pode ser definida a cultura?

Do ponto de vista semiótico, trata-se do conjunto dos processos de produção, circulação e consumo de significações na vida social. Na perspectiva psicanalítica, seria o estilo de recalcamento próprio de cada momento histórico. Para complementar, pode ser acrescentada a noção de subjetividade: a consciência que cada época tem de si mesma, nunca ciente por inteiro e sempre historicamente incompleta.

MPSL: Lacan também teria sido um semioticista?

Ad honorem, hors concours, um artesão da língua, capaz de extrair da clínica os conceitos implícitos em Freud. Além disso conhecia o sistema de Charles Sanders Peirce, também ternário, em grande medida compatível com seu ensino. Formalizando os registros de real, simbólico e imaginário, não apenas consolidou a teoria analítica, assim como estabeleceu um solo firme para as ciências da linguagem e suas decorrências sociais.

LAS: Primeiridade, secundidade $e$ terceiridade coincidem com os três registros lacanianos?

Sim, sim, sim, porém, não! É grande a tentação de plugar esses conceitos, 3x3, mas nem tudo se encaixa - ainda bem. Sistemas complexos podem ser compatibilizados, respeitando contradições e observando incongruências. Da semiótica peirceana provém a definição de signo: algo que significa para alguém, circunstâncias mediante. Por sua vez, Lacan instrumentou, no começo do seu ensino, o signo verbal, graças à linguística de Saussure, por ser o diálogo a condição da análise. Os registros conformam as dimensões habitadas pelos seres falantes, constituindo, na sua amarração, a "realidade", tanto a subjetiva quanto a objetiva, sem garantia de perfeita sintonia. Ser-no-mundo é viver na encruzilhada das palavras, das imagens e das coisas.

MCB: Como se fundamentam e justificam os conceitos derivados da clínica?

O imaginário inclui duas acepções: por um lado, quer dizer falso, fictício; por esse viés, denuncia a ilusão de autonomia do sistema percepção-consciência. Por outro, tem a ver diretamente com as representações e as miragens, matérias-primas das identificações. $\mathrm{Na}$ teoria freudiana, corresponde ao plano do narcisismo, originado na etapa intermediária entre o autoerotismo e as relações objetais da libido. A cristalização da imagem do corpo permite a instalação da matriz do ego no psiquismo; desde então e para sempre essa instância alienada tem acesso à cognição, arcando com o ônus simultâneo do desconhecimento. 
Fora desse âmbito, os sapiens só existem porque falam. O simbólico tem na linguagem sua expressão mais concreta, regendo a sujeição ao inconsciente. Ela é a causa e o efeito da cultura, em que a lei da palavra interdita o incesto e nos torna por completo diferentes dos animais. Na obra de Freud a importância desse registro pode ser destacada, inicialmente, nos textos ilustrativos do funcionamento da outra cena, onde a casuística é a prova da sua estrutura, segundo suas formações: sonhos, atos falhos, chistes, sintomas... Em sintonia, há os textos que discorrem sobre o complexo de Édipo e seu correlato, a castração dependente da função do pai, responsável pela ordem simbólica.

O real, como terceira dimensão, é aludido pela negativa: seria aquilo que, carecendo de sentido, não pode ser simbolizado nem integrado imaginariamente; aquém ou além de qualquer limite, incontrolável e fora de cogitação. A esse respeito, volta outra vez o velho problema da incompatibilidade essencial entre sujeito e objeto: relação impossível, por ser o segundo sobredeterminado, enquanto o primeiro é subvertido pelo desejo. Na metapsicologia, trata-se da base pulsional do isso, ou id, sobre a qual se organiza o aparelho psíquico. Para Freud, a diferença sexual anatômica era a referência-mor. Todavia, o real foi o lugar outorgado ao trauma no começo da psicanálise: aquilo que, por irromper de repente e sem razão, não permite nenhuma defesa eficaz.

GO: Os registros são autônomos? Como se dão entre si?

Os três mosqueteiros! Um por um e uno para todos! Todos diferentes, unidos na sua heterogeneidade por obra e graça de um laço específico, chamado nó borromeano. Três círculos ficam entrelaçados do jeito certo, em torno de uma propriedade pragmática: cortando qualquer deles, os outros dois não ficam juntos, desfazendo a estrutura topológica. Esse tipo de laço é útil para perceber as concatenações e suas lógicas próprias, evitando que sejam considerados por separado, pois funcionam em uníssono. Por ter cada um o seu devido status, nenhum deles teria maior ou menor hierarquia que os outros, atuando de maneira conjunta e se limitando reciprocamente.

NN: Tudo bem, mas como a psicanálise vira semiótica?

A semiótica de extração psicanalítica parte de três ordens de existência que, embora distintas, conformam as matrizes da linguagem e do pensamento: as palavras, as imagens e as coisas. São os elementos constitutivos do mundo humano. Nossa natureza é complexa, nada natural. As palavras são equívocas; as imagens são aparências; as coisas são concretas. Significantes, significados, referentes. No simbólico, $o$ significante representa o sujeito para outro significante; no imaginário, prima o significado, que só faz sentido quando consciente; no real, manca o referente, impossível e profundamente perdido, segundo Freud. Para além do sensível, nem tudo é simbolizável...

A estrutura da realidade humana é tridimensional. A subjetividade decorre da articulação entre a matéria, as formas e a significação. Ainda que a amarração psíquica dos registros seja única e peculiar para cada um, segundo sua própria história e destino, há uma dimensão comum, que permite que os falantes de uma mesma língua partilhem sentidos coletivos, experimentando a vida cotidiana como "normal".

MA: Lembrando Deleuze, qual seria a lógica do sentido?

O sentido é a resultante da junção do simbólico com o imaginário, assimilando o singular de cada um com o plural de todos. Aquilo que tem nome e forma conhecida pode ser compreendido e partilhado. Por oposição e contraste, o real, anônimo e amorfo dispensa denominações ou previsões, impondo-se por poder próprio, independente das intenções 
ou designações humanas. Pode-se entender a cultura, de maneira ampla, como uma gigantesca máquina de produção de sentidos por meio dos aparelhos ideológicos, sejam do Estado ou da iniciativa privada. Os discursos competentes, a doxa, o bom senso, a sensatez, o sentido comum... A lógica do sentido é a alienação, o preço a ser pago por viver em sociedade. No plano subjetivo, ideias e representações só fazem sentido quando não ofendem o narcisismo, consolidando identidades.

OM: $O$ que é a semiótica psicanalítica sintética (SPS)?

Um quadro sinóptico, de dupla entrada, que permite estabelecer convergências e cruzamentos conceituais a partir dos registros. Por exemplo, o imaginário alinhava as categorias de narcisismo-imagemsentido-crença, compatíveis sem serem sinônimas, e assim por diante. Ao mesmo tempo, a leitura horizontal confronta os desdobramentos verticais, distintos.

Quadro 1. Semiótica Psicanalítica Sintética.

\begin{tabular}{|l|l|l|l|l|l|}
\hline \multicolumn{1}{|c|}{ Registro } & \multicolumn{1}{|c|}{ Domínio } & \multicolumn{1}{|c|}{ Matriz } & \multicolumn{1}{|c|}{ Sítio } & \multicolumn{1}{c|}{ Razão } & \multicolumn{1}{c|}{ Ser } \\
\hline Simbólico: & Inconsciente & Palavra & Mente & Saber & Falante \\
\hline Imaginário: & Narcisismo & Imagem & Sentido & Crença & Sexuado \\
\hline Real: & Gozo & Coisa & Cérebro & Conhecimento & Mortal \\
\hline
\end{tabular}

Fonte: Elaborado pelo autor, 2018.

A topologia se ocupa da articulação dos registros da experiência humana; a psicanálise volta-se para os domínios do psiquismo; a semiótica, por sua vez, dirige-se às matrizes de linguagem e pensamento; já as neurociências, aos locais cognitivos; a epistemologia, às razões intelectuais; e a filosofia, às questões ontológicas ligadas à sexuação e à finitude.

Um novo paradigma robusto que unifique sem simplificar deveria levar em consideração todas essas incidências, sempre presentes quando se trata do psiquismo barroco da nossa espécie. Senão, nada feito...

AP: $O$ que se entende por clínica da cultura?

Por ser uma disciplina heurística, a semiótica psicanalítica trabalha com hipóteses retroativas e conjecturas prospectivas. A clínica da cultura faz os diagnósticos, por imagens e palavras, das ideologias da época. São considerados sintomas as contradições da sociedade, seus impasses e soluções de compromisso, cujas manifestações e latências podem ser descritas, analisadas e interpretadas ao pé da letra. A espetacularização do mundo contemporâneo, por meio da proliferação das tecnologias da comunicação, discrepa da realidade globalizada, deixando muito a desejar se consideradas as insuficiências do sistema capitalista para concretizar todo o prometido.

As bases teóricas para essa leitura crítica encontram-se no Mal-estar na cultura, de Freud; nos quatro discursos de Lacan; e nos ensaios de Zizek, dentre os mais destacados. Trata-se, em definitivo, da psicanálise em expansão.

ALG: Para que serve o curso Semiótica Psicanalítica - Clínica da Cultura?

Lato sensu, uma especialização em... (após o curso, o desejo individual preenche este destino). Seu objetivo é a disseminação de ideias originais, necessárias para se entender o século XXI, do qual fazemos parte como sujeitos históricos e seres gozosos, capazes de aprender a sobreviver e mudar a vida com alegria. 
MC: Exteriormente à PUC, a semiótica psicanalítica floresce em algum outro território?

Sim. Cumprindo o vaticínio de Umberto Eco, a semiose avança: em 2018, na Escola de Comunicações e Artes da Universidade de São Paulo (ECA-USP), foi iniciada uma especialização inédita, Cultura Material e Consumo - Perspectivas semiopsicanalíticas, organizada por Clotilde Perez. Quais seriam as ressonâncias e as distinções entre os dois cursos? Enquanto o primeiro centra o foco na esfera vivida pelos sujeitos sujeitados, o novo aponta às consequências da relação com os objetos da necessidade, do desejo e da fruição, onipresentes na vida cotidiana, nos sonhos e nos ideais.

SH: Bom, depois de tudo isso, ainda seria possível ser feliz?

Claro que sim! Tudo depende "da gente" (de cada um e de todos). A felicidade, definida por Renata Salecl, uma das autoras da nossa bibliografia, também é um item de consumo na contemporaneidade. Entretanto, ética e existencialmente, resta para cada um, um por um, saber qual é o verdadeiro custo da vida, da própria e da alheia, lembrando sempre uma das máximas de Maio de 1968: a liberdade dos outros expande a minha até $o$ infinito. Tim-tim! 